\title{
(2) OPEN ACCESS \\ Deprivation matters: understanding associations between neighbourhood deprivation, unhealthy food outlets, unhealthy dietary behaviours and child body size using structural equation modelling
}

\author{
Victoria Egli (10, ${ }^{1}$ Matthew Hobbs $\mathbb{C}^{2}{ }^{2}$ Jordan Carlson, ${ }^{3}$ Niamh Donnellan, ${ }^{1}$ \\ Lisa Mackay, ${ }^{4}$ Daniel Exeter, ${ }^{5}$ Karen Villanueva, ${ }^{6}$ Caryn Zinn, ${ }^{4}$ Melody Smith ${ }^{1}$
}

- Additional material is published online only. To view please visit the journal online (http://dx.doi.org/10.1136/ jech-2019-213159).

For numbered affiliations see end of article.

\section{Correspondence to} Dr Victoria Egli, School of Nursing, The University of Auckland Faculty of Medical and Health Sciences, Auckland, New Zealand; v.egli@auckland.ac.nz

Received 1 September 2019 Revised 19 December 2019 Accepted 6 February 2020
Check for updates

(C) Author(s) (or their employer(s)) 2020. Re-use permitted under CC BY-NC. No commercial re-use. See rights and permissions. Published by BMJ.

To cite: Egli V, Hobbs M, Carlson J, et al. J Epidemiol Community Health

2020;74:460-466.

\section{ABSTRACT}

Background Children residing in neighbourhoods of high deprivation are more likely to have poorer health, including excess body size. While the availability of unhealthy food outlets are increasingly considered important for excess child body size, less is known about how neighbourhood deprivation, unhealthy food outlets and unhealthy dietary behaviours are interlinked.

Methods This study involves children aged 8-13 years $(n=1029)$ and resided in Auckland, New Zealand. Unhealthy dietary behaviours (frequency of consumption of unhealthy snacks and drinks) and food purchasing behaviour on the route to and from school were self-reported. Height and waist circumference were measured to calculate waist-toheight ratio (WtHR). Geographic Information Systems mapped neighbourhood deprivation and unhealthy food outlets within individual, child-specific neighbourhood buffer boundaries $(800 \mathrm{~m}$ around the home and school). Associations between neighbourhood deprivation (calculated using the New Zealand Index of Deprivation 2013), unhealthy food outlets, unhealthy dietary behaviours and WtHR were investigated using structural equation modelling in Mplus V.8.0. Age, sex and ethnicity were included as covariates, and clustering was accounted for at the school level.

Results Structural equation models showed that unhealthy food outlets were unrelated to unhealthy dietary behaviours (estimate $0.029, p=0.416$ ) and excess body size (estimate $-0.038, p=0.400$ ). However, greater neighbourhood deprivation and poorer dietary behaviours (estimate $-0.134, p=0.001$ ) were associated with greater WtHR (estimate 0.169, $\mathrm{p}<0.001$ )

Conclusion Excess child body size is associated with neighbourhood deprivation and unhealthy dietary behaviours but not unhealthy outlet density or location of these outlets near home and school.

\section{INTRODUCTION}

Individuals residing in deprived areas experience poorer health and worse social outcomes than their counterparts in less deprived areas ${ }^{1}$ and children are disproportionately and negatively affected by deprivation. $^{2}$ Every child is entitled to a high standard of living for physical, mental, spiritual, moral and social development ${ }^{3} ; 30$ years ago, New
Zealand/Aotearoa (NZ) was one of the first to ratify the United Nations (UN) Convention on the Rights of the Child. NZ, alongside 193 other countries, is also a signatory to the UN Sustainable Development Goals (SDGs). Goal one of the SDGs is to eradicate poverty. ${ }^{4}$ Worldwide children are more likely than adults to live in neighbourhoods of high deprivation and come from income poor households. ${ }^{5}$ In NZ, estimates show around $27 \%$ of children live in income poor households, many of which cluster together in deprived areas. ${ }^{67}$

Businesses selling unhealthy food and drinks target children, ${ }^{8}$ population groups on low incomes and those living and working in deprived neighbourhoods. ${ }^{9}$ In $\mathrm{NZ}$ and other high-income countries, unhealthy food outlets such as fastfood or takeaway restaurants and convenience stores that sell predominately energy dense, nutrient poor foods and beverages ${ }^{10}$ are more likely to be found in highly deprived neighbourhoods. ${ }^{11-13}$ Moreover, food purchasing behaviour is important to consider as systematic reviews show associations between eating out of home and higher overall energy intake ${ }^{14}$ and poorer overall diet quality. ${ }^{15}$ Globally, and in NZ, excess body size in children is a public health concern. ${ }^{16}$ However, the links between deprivation, food purchasing behaviours, unhealthy food environments and excess body size are complex and are seldom considered together.

This research seeks to understand the associations between neighbourhood deprivation, unhealthy food outlets, unhealthy dietary behaviours and excess body size in children. As there is research showing harm caused to children from ubiquitous use of the terms overweight and obesity, ${ }^{17}$ excess body size will be used to refer to greater risk of central adiposity. This research builds on previous cross-sectional studies showing small but significant associations between such food outlets, unhealthy dietary behaviours and increased child and adolescent body size, ${ }^{15} 1819$ and on recent studies in adults ${ }^{20}$ where there was a greater focus on area deprivation in the analysis. Typically, previous studies account for deprivation, independent of potential sociodemographic confounders such as age, ethnicity and sex in regression analyses. Given the complexity of possible associations between deprivation and sociodemographic confounders, we extend the framework 


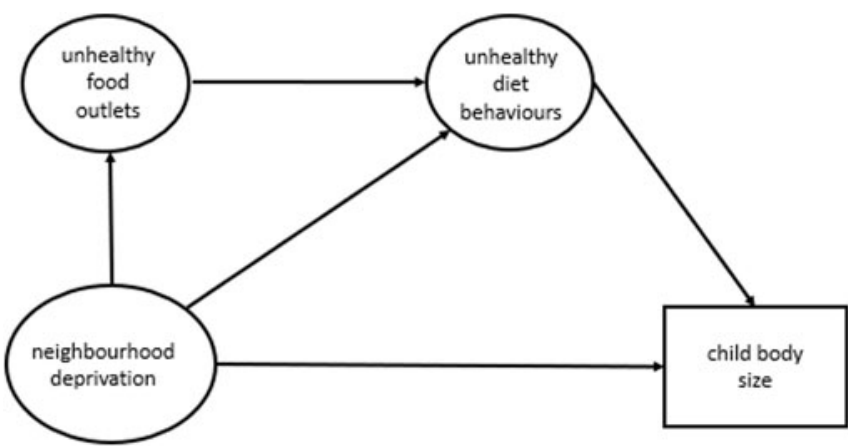

Figure 1 Conceptual model.

proposed (for the adult population) by Hobbs $e t a l^{20}$ and use structural equation modelling (SEM) to quantitatively examine these relationships (see figure 1).

\section{METHODS \\ Study location}

This research was conducted in Auckland, NZ. Approximately one-third of all New Zealanders live in Auckland; it is NZ's largest city with a geographically, ethnically and socioeconomically diverse population of over 1.5 million people (approximately $37.5 \%$ of the total NZ population). ${ }^{21}$ The results from the 2013 Census show that Auckland contains the wealthiest areas in $\mathrm{NZ}$ and the poorest, ${ }^{22}$ often juxtaposed in close proximity to each other. ${ }^{23}$ This makes Auckland an ideal location to study possible associations between neighbourhood deprivation, food outlets, unhealthy dietary behaviours and body size.

\section{Participants}

Children in this study were involved in the cross-sectional Neighbourhoods for Active Kids (NfAK) study which has been described previously. ${ }^{24}$ Briefly, children aged 8-13 years were recruited from 9 intermediate schools (middle/ junior high, school years 7-8: approximate ages 10-13 years) and 10 primary schools (elementary schools, school years 5-6: approximate ages 8-10 years). A matrix was used to select schools maximising variation in socioeconomic and neighbourhood built environment characteristics, specifically walkability, ${ }^{25}$ school decile and destination accessibility. ${ }^{26}$ Participants were invited following consent from a school representative. Students from classes of appropriate school years (as selected by the school) were subsequently visited at the school by researchers during class time, provided with verbal and written information about the study and invited to participate. ${ }^{24}$

\section{Protocol}

This study recognises the rights of the child ${ }^{3}$ and uses a childcentred approach to undertaking research with children. ${ }^{27}$ The survey was piloted prior to data collection $^{28}$ and data were collected between February (the start of the school year) 2015 and September 2016. Trained researchers visited participating schools during school hours, and following standard operating procedures they provided child participants one-on-one assistance to complete an online survey and measured participant height (using a stadiometer) and waist circumference (using a Lufkin tape measure). Information on child ethnicity and school decile were obtained from the school and New Zealand Ministry of Education, respectively.

\section{Measures}

Defining and measuring neighbourhoods is fraught with challenges, as neighbourhoods are not constant across all people, places and time. ${ }^{29}$ Globally, food environment researchers have used a wide range of buffer distances from $100 \mathrm{~m}$ to $3.2 \mathrm{~km} .{ }^{30}$ Mavoa $^{31}$ tested associations between built environment factors and child physical activity in NZ using different road network buffers around the home and found that the 500 or $800 \mathrm{~m}$ road network buffer was most aligned with child physical activity and gave the greatest likelihood of significant findings. Research from NZ also suggests that schools are important central components of children's neighbourhoods 3233 and important to consider alongside homes in determining children's activity spaces and neighbourhood food environments. ${ }^{30} 3435$ In this study, neighbourhoods were calculated by the combination of an $800 \mathrm{~m}$ road network buffer around the child's home and an $800 \mathrm{~m}$ road network buffer around all entrances to the child's school less any area of overlap. Neighbourhood calculations were made in ArcGIS V.10.5.1 (ESRI, Redlands, California, USA). ${ }^{31} 36$ An example neighbourhood can be seen figure 2 .

All GIS data sources are reported in online supplementary material file 1.

Neighbourhood deprivation was calculated using the New Zealand Index of Deprivation (NZDep2013), a composite measure that comprises nine variables (personal and household income, home ownership, employment, qualifications, family structure, housing, access to transport and communications) derived from the 2013 Census in New Zealand. ${ }^{37}$ Each meshblock was assigned a decile of deprivation, in which decile 1 represents the least deprived 10\% of meshblocks across NZ and decile 10 represents the most deprived $10 \%$ of meshblocks. For this study, an average neighbourhood level area deprivation score for participants was calculated. Specifically, all NZDep2013 scores of meshblocks that intersected the neighbourhood buffer were summed and divided by the number of meshblocks within each neighbourhood. The neighbourhood average was then categorised into tertiles in which 'low deprivation' comprised deciles 1-3; 'medium deprivation' included deciles 4-7 and 'high deprivation' comprised deciles 8-10.

Body size was measured by research assistants in order to calculate waist-to-height ratio (WtHR; waist circumference/ height). Waist circumference was taken with a Lufkin tape measure recorded correct to nearest $0.1 \mathrm{~cm}$. Height in centimetres was assessed using a stadiometer to the nearest $0.1 \mathrm{~cm}$. Each measure was recorded twice, and a third measurement was taken when the two previous measures differed by more than $0.5 \mathrm{~cm}$. A WtHR threshold of 0.5 was used to determine increased health risk associated with central adiposity and the outcome variable was dichotomised accordingly: $1 \leq 0.5,2$ $\geq 0.51$. $^{38}$ Age was recorded in years. Ethnicity was classified according to the Ministry of Education New Zealand, level 1 prioritisation. $^{39}$

The latent variable, 'unhealthy food outlets' included three items. Item A measured the density of unhealthy food outlets and was calculated using data from a national database of food outlets, consistent with other studies of food environments in $\mathrm{NZ}{ }^{35}$ In NZ, all food outlets must be registered with a national database for regular checking of food safety. ${ }^{35}$ We defined unhealthy food outlets as fast-food, convenience or takeaway stores. Specifically, density was calculated as the count of unhealthy food outlets divided by the area of the combined neighbourhood buffer. Item B measured the shortest distance in metres along the road network from each participant's home address to their nearest unhealthy food outlet. Item $\mathrm{C}$ measured 


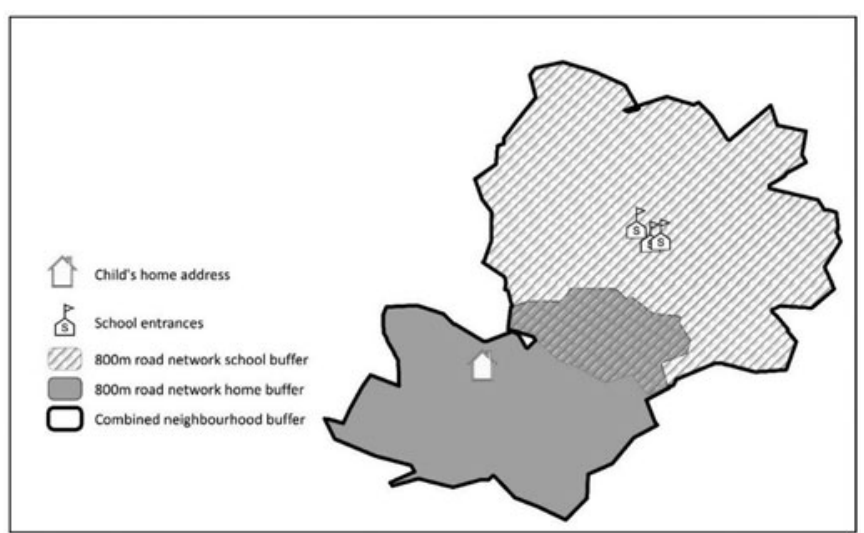

Figure 2 An example neighbourhood.

the shortest distance in metres along the road network from the participant's school to the nearest unhealthy food outlet.

The latent variable, 'unhealthy diet behaviours' had four items that captured food purchasing behaviour en-route to and from school as well as the frequency of consumption of unhealthy snacks (eg, biscuits, chocolate, lollies, chips) and/or sugar-sweetened beverages (eg, juice, cola, flavoured milks). Each question was coded 1-5 initially, but for this study we dichotomised each question as $0=$ frequent consumption (every day or every week) or 1 =infrequent consumption (every month, hardly ever/never). For specific questions and response options, please see online supplementary material file 2 .

\section{Analysis}

A confirmatory factor analysis was completed on the observed variables for each latent construct. Some observed variables within latent constructs were measured on different scales, therefore $\mathrm{z}$ scores were created to standardise items to have a mean of 0 and SD of 1 . The conceptual model is presented in figure 1. Clustering was accounted for at the level of the school using the 'complex samples analysis' approach.

\section{RESULTS}

A total of 2534 participants were invited to participate in this study and 1102 provided assent and parental consent (43.5\%). Cases with missing $(n=42)$ or out-of-range WtHR values $(n=1)$ were removed, leaving 1029 participants in the analytic sample. Descriptive statistics of participant characteristics are detailed in table 1 . In brief, there were fairly even distributions by gender, and between primary and intermediate school students. Table 2 shows that most children had a WtHR $<0.5$. When analysed as a continuous variable, the overall mean WtHR was 0.456 (SD 0.062 ). The mean WtHR was 0.44 for children residing in the least deprived (tertile 1 ) and 0.49 for children living in middle and high deprived neighbourhoods (tertiles 2 and 3). Descriptive statistics stratified by WtHR can be seen in table 2 .

The SEM indicated good model fit; the root mean square error of approximation was 0.012 (90\% CI 0.000-0.023); the Comparative Fit Index (CFI) was 0.950 and Tucker-Lewis index (TLI) was 0.920 . All model results are presented in table 3. The estimates and standard errors were derived from a series of models, estimated simultaneously, for which both the independent and dependent variables were standardised.

A summary of significant associations between neighbourhood deprivation and child body size and the latent variables unhealthy food outlets and unhealthy dietary behaviours are presented in
Table 1 Descriptive statistics of participants

\begin{tabular}{|c|c|}
\hline Characteristic & n (\%) \\
\hline Total children & $1029(100)$ \\
\hline \multicolumn{2}{|l|}{ School type } \\
\hline Intermediate & $485(47.1)$ \\
\hline Primary & $544(52.9)$ \\
\hline \multicolumn{2}{|l|}{ School decile* } \\
\hline Low (most deprived 1-3) & $270(26.2)$ \\
\hline Mid (4-7) & $242(23.5)$ \\
\hline High (least deprived 8-10) & $517(50.3)$ \\
\hline \multicolumn{2}{|l|}{ Neighbourhood deprivation* } \\
\hline Least deprived (1-3) & $418(40.6)$ \\
\hline Mid (4-7) & $394(38.3)$ \\
\hline Most deprived $(*, 9,10)$ & $209(20.3)$ \\
\hline \multicolumn{2}{|l|}{ Sex } \\
\hline Male & $505(49.1)$ \\
\hline Female & $529(50.9)$ \\
\hline \multicolumn{2}{|l|}{ Ethnicity } \\
\hline Māori & $120(11.7)$ \\
\hline Pacific peoples & $141(13.7)$ \\
\hline Asian & $138(13.4)$ \\
\hline $\begin{array}{l}\text { Middle Eastern/ } \\
\text { Latin American/ } \\
\text { African }\end{array}$ & $24(2.3)$ \\
\hline Other & $4(0.4)$ \\
\hline $\begin{array}{l}\text { NZ European/other } \\
\text { European }\end{array}$ & $435(42.3)$ \\
\hline Not stated & $167(16.2)$ \\
\hline \multicolumn{2}{|l|}{ Body size outcome variable } \\
\hline \multicolumn{2}{|l|}{ Waist-to-height ratio } \\
\hline$<0.5$ & $860(83.6)$ \\
\hline$>0.51$ & $169(16.4)$ \\
\hline
\end{tabular}

*School decile ratings in NZ are inverse to NZDep2013 ratings (1=low, 10=high) indicating the extent to which the school draws its students from low socioeconomic communities. ${ }^{39}$ This means a decile 1 school comes from $10 \%$ of schools in NZ with the highest proportion of students from highly deprived communities. Conversely, a decile 10 school comes from $10 \%$ of schools with the lowest proportion of these students. School deciles are used predominantly for government allocation of funding and cannot be used as a sole indicator of area level deprivation, thus NZDep2013 was also used.

NZ, New Zealand; NZDep2013, New Zealand Index of Deprivation.

figure 3. Greater neighbourhood deprivation (estimate 0.169, $\mathrm{p}<0.001$ ) and unhealthy dietary behaviours (estimate -0.134 , $\mathrm{p}<0.001)$ were independently related to greater WtHR. There was no association between area level deprivation and unhealthy food outlets (estimate 0.044, p=0.880), or neighbourhood deprivation and unhealthy dietary behaviours (estimate 0.053 , $\mathrm{p}=0.590$ ). There was also no significant association between unhealthy food outlets and unhealthy dietary behaviours (estimate $0.029, p=0.146$ ). Pacific children were more likely to have a greater WtHR (estimate $0.191, \mathrm{p}=0.017$ ). No significant associations were found between the covariates and age or sex.

\section{DISCUSSION}

This study adds new knowledge by using SEM to investigate associations between neighbourhood deprivation, unhealthy food outlets, unhealthy dietary behaviours and excess body size in a large sample of children with measured WtHR. The effect size of the association between neighbourhood deprivation and unhealthy dietary behaviours on excess body size was 
Table 2 Descriptive statistics for observed variables by waist-to-height ratio

\begin{tabular}{|c|c|c|c|c|}
\hline & & \multicolumn{3}{|l|}{ Body size } \\
\hline & & $\begin{array}{l}\text { Waist-to-height ratio }<0.5 \\
(\mathrm{n}=860)\end{array}$ & $\begin{array}{l}\text { Waist-to-height ratio }>0.51 \\
(\mathrm{n}=169)\end{array}$ & $\begin{array}{l}\text { Total } \\
(\mathrm{n}=1029)\end{array}$ \\
\hline & & Mean (SD) & Mean (SD) & Mean (SD) \\
\hline \multicolumn{5}{|l|}{ Unhealthy food outlets } \\
\hline Density & Count & $7.20(4.76)$ & $7.63(7.99)$ & $2.77(4.80)$ \\
\hline Distance to nearest from home & Metres & $575(637)$ & $499(387)$ & $562(604)$ \\
\hline \multirow[t]{2}{*}{ Distance to nearest from school } & Metres & $372(219)$ & $384(206)$ & $374(217)$ \\
\hline & & $\mathrm{n}(\%)$ & $\mathrm{n}(\%)$ & $\mathrm{n}(\%)$ \\
\hline \multicolumn{5}{|l|}{ Unhealthy dietary behaviours } \\
\hline \multirow[t]{2}{*}{ Frequency of consumption of unhealthy drinks } & Every day and every week & 762 (88.6) & $138(81.7)$ & $900(87.5)$ \\
\hline & Every month and hardly ever/never & $98(11.4)$ & $31(18.3)$ & $129(12.5)$ \\
\hline \multirow[t]{2}{*}{ Frequency of consumption of unhealthy snacks } & Every day and every week & $697(81.0)$ & $140(82.8)$ & $837(81.3)$ \\
\hline & Every month and hardly ever/never & $163(19.0)$ & $29(17.2)$ & $192(18.7)$ \\
\hline \multirow[t]{2}{*}{ Food purchasing behaviour on the way to school } & Every day and every week & $843(98.0)$ & $159(92.9)$ & $1000(97.2)$ \\
\hline & Every month and hardly ever/never & $17(2.0)$ & $12(7.1)$ & $29(2.8)$ \\
\hline \multirow[t]{2}{*}{ Food purchasing behaviour on the way from school } & Every day and every week & $829(96.4)$ & $158(93.5)$ & $987(95.9)$ \\
\hline & Every month and hardly ever/never & $31(3.6)$ & $11(6.5)$ & $42(4.1)$ \\
\hline
\end{tabular}

approximately equal. This supports emerging evidence on the negative impact of inequality on child health outcomes ${ }^{2}{ }^{6}$ and calls to increase action to reduce neighbourhood deprivation from two perspectives: (1) child's rights and (2) to prevent excess body size and the associated negative health impacts across the life course. This research reinforces the importance of neighbourhood deprivation as a correlate in the analysis of environmental impacts on child body size outcomes, despite a finding of lack of association between unhealthy food outlets and unhealthy dietary behaviours.

Neighbourhood deprivation and unhealthy dietary behaviours had the strongest relationship with excess body size among children in our study. The effect sizes were approximately equal. This finding differs to the work of Hobbs et $a l^{20}$ on which the theoretical framework of this study was modelled. Hobbs et al found greater effect sizes for deprivation than unhealthy food outlets on the excess body size of adults. Nonetheless, the extent to which the difference between these statistically significant effect sizes matters in practice is unclear ${ }^{40}$ and requires further investigation.

Contrary to previous research, ${ }^{19}$ our study found no association between the location and density of unhealthy food outlets and child body size which mirrors internationally inconsistent evidence. ${ }^{41}$ This finding could be due to the local context in Auckland, NZ where there appears to be increased accessibility to all food outlets in neighbourhoods of high deprivation. ${ }^{13}$ Future modelling could consider using all food outlets, rather than only those offering predominantly unhealthy food items, as opportunities exist to purchase unhealthy food and drink in outlets selling predominantly as 'healthy' food or drink.

It is also possible that no relationship exists between the location and/or density of unhealthy food outlets and child body size and that is why it was not detected. Furthermore, other factors related to child body size such as epigenetics, sleep, food habits and physical activity should also be more comprehensively included in future modelling. Research using more complex/ multidimensional picture of person and place $^{42}$ may be required to detect such associations.
This study uses a novel approach to defining individualised neighbourhood buffers that include the area around both the child's home and school using an $800 \mathrm{~m}$ road network boundary. A more precise method of capturing children's actual movement in their neighbourhood and determining neighbourhood boundaries could be achieved through GPS logging and should be considered in future research studies of children's food environments. This method was not used in NfAK due to a lack of feasibility. It is also possible that loss of precision may have occurred through the transformation of neighbourhood deprivation from a continuous variable into the categorical variable deprivation tertiles. However, low, medium and high categories of deprivation are commonly used in the food environment literature ${ }^{4344}$ and are particularly useful to make relative comparisons for policymakers and practitioners. While we build toward greater complexity, a better understanding of connections between neighbourhood deprivation and child poverty and body size are warranted in future research.

Food purchasing behaviour was included alongside the frequency of consumption of energy dense, nutrient poor snacks and sugar-sweetened beverages as the location of unhealthy food outlets near schools has been linked to lunchtime food purchasing behaviour and consumption ${ }^{45}$ and the within school food environment. ${ }^{46}$ Our analysis found no association between these food outlets and food purchasing behaviour, however unhealthy dietary behaviours was significantly associated with likelihood of excess body size. Further research into the food purchasing behaviour of children, including the level of independence children have when purchasing food, would yield important insights into contemporary dietary health behaviours and help identify areas for prevention efforts.

The findings of this study have important implications for future research, but policymakers in public health, land use planners and others interested in creating healthy environments should interpret the results of this study with caution. First, children attending schools in neighbourhoods of deprivation in Australia and NZ are significantly more likely than their peers in 
Table 3 Results from structural equation model

\begin{tabular}{|c|c|c|c|c|}
\hline & Standardised estimate & SE & Estimated SE & Two-tailed $p$ value \\
\hline \multicolumn{5}{|l|}{ CFA loadings for the unhealthy food outlet latent construct } \\
\hline Unhealthy outlet density & 0.575 & 0.141 & 4.086 & $<0.001$ \\
\hline Unhealthy outlet distance from home & 0.560 & 0.148 & 3.770 & $<0.001$ \\
\hline Unhealthy outlet distance from school & 0.575 & 0.297 & 1.939 & 0.053 \\
\hline \multicolumn{5}{|l|}{ CFA loadings for the unhealthy dietary behaviours latent construct } \\
\hline Purchase on the way to school & 0.768 & 0.080 & 9.584 & $<0.001$ \\
\hline Purchase on the way from school & 0.864 & 0.090 & 9.625 & $<0.001$ \\
\hline Unhealthy snack consumption & 0.209 & 0.067 & 3.128 & 0.002 \\
\hline Unhealthy drink consumption & 0.477 & 0.045 & 10.632 & $<0.001$ \\
\hline \multicolumn{5}{|l|}{$\begin{array}{l}\text { DV: Unhealthy dietary behaviours } \\
\text { IVs: }\end{array}$} \\
\hline Neighbourhood deprivation tertile & 0.053 & 0.098 & 0.538 & 0.590 \\
\hline Age & -0.020 & 0.086 & -0.228 & 0.820 \\
\hline Sex & 0.000 & 0.032 & -0.002 & 0.998 \\
\hline \multicolumn{5}{|l|}{ Ethnicity } \\
\hline Māori & 0.000 & 0.067 & 0.005 & 0.996 \\
\hline Pacific peoples & 0.002 & 0.079 & 0.024 & 0.981 \\
\hline Asian & 0.000 & 0.075 & -0.004 & 0.997 \\
\hline MELAA & 0.000 & 0.048 & 0.001 & 1.000 \\
\hline Other & 0.000 & 0.109 & 0.000 & 1.000 \\
\hline European & 0.000 & 0.088 & -0.003 & 0.998 \\
\hline \multicolumn{5}{|l|}{$\begin{array}{l}\text { DV: Unhealthy food outlets } \\
\text { IVs: }\end{array}$} \\
\hline Neighbourhood deprivation tertile & 0.044 & 0.290 & 0.151 & 0.880 \\
\hline Age & -0.019 & 0.202 & -0.093 & 0.926 \\
\hline Sex & 0.000 & 0.032 & -0.002 & 0.999 \\
\hline \multicolumn{5}{|l|}{ Ethnicity } \\
\hline Māori & 0.000 & 0.192 & 0.002 & 0.999 \\
\hline Pacific peoples & 0.002 & 0.189 & 0.008 & 0.993 \\
\hline Asian & 0.000 & 0.218 & -0.001 & 0.999 \\
\hline MELAA & 0.000 & 0.114 & 0.000 & 1.000 \\
\hline Other & 0.000 & 0.079 & 0.000 & 1.000 \\
\hline European & 0.000 & 0.220 & -0.001 & 0.999 \\
\hline $\begin{array}{l}\text { Correlation between unhealthy food outlets and unhealthy dietary } \\
\text { behaviours }\end{array}$ & 0.029 & 0.035 & 0.814 & 0.416 \\
\hline $\begin{array}{l}\text { Correlation between waist-to-height ratio and unhealthy dietary } \\
\text { behaviours }\end{array}$ & -0.134 & 0.040 & -3.356 & 0.001 \\
\hline Correlation between waist-to-height ratio and unhealthy food outlets & -0.038 & 0.045 & -0.842 & 0.400 \\
\hline \multicolumn{5}{|l|}{$\begin{array}{l}\text { DV: Waist-to-height ratio } \\
\text { IVs: }\end{array}$} \\
\hline Neighbourhood deprivation tertile & 0.169 & 0.047 & 3.582 & $<0.001$ \\
\hline Age & -0.024 & 0.061 & -0.388 & 0.698 \\
\hline Sex & -0.074 & 0.048 & -1.541 & 0.123 \\
\hline \multicolumn{5}{|l|}{ Ethnicity } \\
\hline Māori & 0.088 & 0.076 & 1.154 & 0.249 \\
\hline Pacific peoples & 0.191 & 0.080 & 2.392 & 0.017 \\
\hline Asian & -0.038 & 0.077 & -0.488 & 0.626 \\
\hline MELAA & -0.025 & 0.045 & -0.554 & 0.580 \\
\hline Other & -0.004 & 0.041 & -0.102 & 0.919 \\
\hline European & -0.186 & 0.126 & -1.474 & 0.140 \\
\hline
\end{tabular}

CFA, Confirmatory Factor Analysis; DV, Dependent variable; IV, Independent variable; MELAA, Middle Eastern, Latin American, African.

more privileged neighbourhoods to be exposed to unhealthy food outlets. ${ }^{11} 35$ However, the direct connection between increased exposure to these food outlets and unhealthy dietary behaviours of children has not yet been shown. This study used count densities of unhealthy food outlets in children's neighbourhoods and assessing relative densities of unhealthy food outlets to 


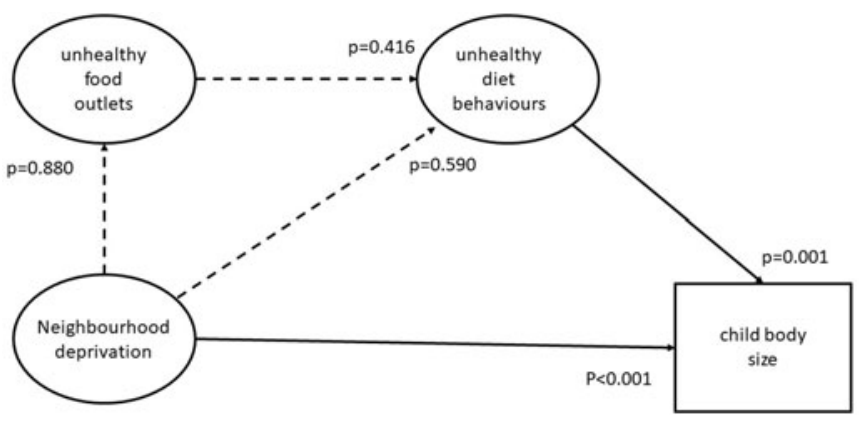

Figure 3 A summary of significant associations.

all food outlets may provide additional insight. Public health practitioners, schools and community groups have long advocated for greater restrictions around the location and density of unhealthy food outlets near places regularly frequented by children ${ }^{16}$ and more research is needed to determine the mechanisms through which exposure to such outlets and marketing of unhealthy food directly or indirectly influences dietary behaviour. In depth, qualitative and observational studies could provide unique insights and could be both culturally appropriate and child-centred. Furthermore, given the known bidirectional influences children and parents have on household and out-of-home food purchases, ${ }^{47}$ greater attention should be given to the food purchasing behaviour of children and parents from food outlets within children's neighbourhoods and from food outlets outside of children's neighbourhoods.

This research showed a significant association between neighbourhood deprivation and excess child body size. There is a clear need to reduce rates of children experiencing deprivation in NZ. It may be that interventions targeting overall reductions in child deprivation have a number of follow-on benefits to child health, including but not limited to body size. Investigations into social inequality, as well as household income and food insecurity on child body size, also warrant further research, particularly given the high numbers of children who currently reside in areas of deprivation and live in income poor households in NZ. ${ }^{6}$

\section{What is already known on this subject}

- Unhealthy neighbourhood food environments are increasingly considered linked with excess child body size.

- Few studies consider the pathways linking neighbourhood deprivation, unhealthy food outlets, unhealthy dietary behaviours and excess body size.

\section{What this study adds}

- This study reinforces the importance of neighbourhood deprivation for excess child body size when considered alongside other neighbourhood influences such as unhealthy food outlets.

- This is the first study to use individualised (home and school) neighbourhood buffer boundaries in the assessment of unhealthy food outlets and measured child body size outcomes in a structural equation model.

- Results confirm the important influence of neighbourhood deprivation and unhealthy dietary behaviours with excess child body size.

\section{CONCLUSION}

This study uses SEM to investigate associations between neighbourhood deprivation, unhealthy food outlets, unhealthy dietary behaviours and excess body size in a large sample of children, aged 8-13 years, residing in geographically varied neighbourhoods in Auckland, NZ. Neighbourhood deprivation and unhealthy dietary behaviours were associated with excess body size but not with density and location of unhealthy food outlets. This research reinforces the importance of neighbourhood deprivation alongside unhealthy dietary behaviours as a correlate of environmental impacts on child body size outcomes.

\section{Author affiliations}

${ }^{1}$ School of Nursing, The University of Auckland Faculty of Medical and Health Sciences, Auckland, New Zealand

${ }^{2}$ GeoHealth Laboratory, Geospatial Research Institute, University of Canterbury, Christchurch, New Zealand

${ }^{3}$ Center for Children's Healthy Lifestyles \& Nutrition, Children's Mercy, Kansas City, Missouri, USA

${ }^{4}$ School of Sport and Recreation, Auckland University of Technology Faculty of Health and Environmental Sciences, Auckland, New Zealand

${ }^{5}$ Epidemiology and Biostatistics, The University of Auckland Faculty of Medical and Health Sciences, Auckland, New Zealand

${ }^{6}$ Centre for Urban Research, Royal Melbourne Institute of Technology, Melbourne, Victoria, Australia

Correction notice The images for figure 1 and figure 3 were published the wrong way around. This has been corrected in the current version online. However, the print version is incorrect.

Twitter Victoria Egli @EgliVictoria and Matthew Hobbs @hobbs_PA

Contributors VE, MS, LM, CZ and KV contributed to the initial study design. VE, LM and $\mathrm{ND}$ contributed to preliminary data analysis and VE, JC, DE, MS and MH contributed to the modelling. All authors contributed to the manuscript and approved the final version prior to submission.

Funding This study was supported by a Health Research Council of New Zealand grant (grant number 14/436). MS is supported by a Health Research Council of New Zealand Sir Charles Hercus Research Fellowship (grant number 17/013).

\section{Competing interests None declared.}

\section{Patient consent for publication Not required.}

Ethics approval Ethical approval to conduct the study was provided by the host institution ethics committees (AUT Ethics Committee 14/263, 3 September 2014; Massey University Human Ethics Committee, 3 September 2014; University of Auckland Human Participant Ethnics Committee, 9 September 2014).

Provenance and peer review Not commissioned; externally peer reviewed.

Data availability statement No data are available. We do not have permission from the participants to share this data in whole or in part.

Open access This is an open access article distributed in accordance with the Creative Commons Attribution Non Commercial (CC BY-NC 4.0) license, which permits others to distribute, remix, adapt, build upon this work non-commercially, and license their derivative works on different terms, provided the original work is properly cited, appropriate credit is given, any changes made indicated, and the use is noncommercial. See: http://creativecommons.org/licenses/by-nc/4.0/.

\section{ORCID iDs}

Victoria Egli http://orcid.org/0000-0002-3306-7709

Matthew Hobbs http://orcid.org/0000-0001-8398-7485

\section{REFERENCES}

1 Ministry of Health. New Zealand Health Survey: Annual Data Explorer 2017/18, 2019. Available: https://minhealthnz.shinyapps.io/nz-health-survey-2017-18-annual-data-e xplorer/.

2 Wickham S, Anwar E, Barr B, et al. Poverty and child health in the UK: using evidence for action. Arch Dis Child 2016;101:759-66

3 UNICEF. Convention on the rights of the child. 1989.

4 United Nations,. Sustainable development goals report 20162016.

5 Roser M, Ortiz-Ospina E. Global extreme poverty. Our World in Data 2017:1-38.

6 Duncanson M. Child Poverty Monitor 2018: Technical Report (National Report). In: service NZCaYE, ed. Otago, New Zealand, 2018. 
7 Exeter DJ, Zhao J, Crengle S, et al. The New Zealand indices of multiple deprivation (IMD): a new suite of indicators for social and health research in Aotearoa, New Zealand. PLoS One 2017;12:e0181260.

8 Coates A, Boyland EJ. Food Marketing to Young Children, in The Psychology of Food Marketing and Overeating. In: Folkvord F, ed. NY, USA: Routledge, 2019.

9 Harris JL, Pomeranz JL, Lobstein T, et al. A crisis in the marketplace: how food marketing contributes to childhood obesity and what can be done. Annu Rev Public Health 2009;30:211-25.

10 World Health Organization. Healthy diet. 2015. Fact sheet No. 394 (Updated September 2015).

11 Coffee NT, Kennedy HP, Niyonsenga T. Fast-food exposure around schools in urban Adelaide. Public Health Nutr 2016;19:3095-105.

12 Sushil Z, Vandevijuere S, Exeter DJ, et al. Food swamps by area socioeconomic deprivation in New Zealand: a national study. Int J Public Health 2017;62:869-77.

13 Wiki J, Kingham S, Campbell M. Accessibility to food retailers and socio-economic deprivation in urban New Zealand. N Z Geog 2019;75:3-11.

14 Lachat C, Nago E, Verstraeten R, et al. Eating out of home and its association with dietary intake: a systematic review of the evidence. Obesity Reviews 2012;13:329-46.

15 Carroll-Scott A, Gilstad-Hayden K, Rosenthal L, et al. Disentangling neighborhood contextual associations with child body mass index, diet, and physical activity: the role of built, socioeconomic, and social environments. Soc Sci Med 2013;95:106-14.

16 Kelly S, Swinburn B. Childhood obesity in New Zealand. N Z Med J 2015;128:6-7.

17 Pont SJ, Puhl R, Cook SR, et al. Stigma experienced by children and adolescents with obesity. Pediatrics 2017;140:e20173034.

18 Ghenadenik AE, Kakinami L, Van Hulst A, et al. Neighbourhoods and obesity: a prospective study of characteristics of the built environment and their association with adiposity outcomes in children in Montreal, Canada. Prev Med 2018;111:35-40.

19 Hamano T, et al, Association between childhood obesity and neighbourhood accessibility to fast-food outlets. A nationwide 6-year follow-up study of 944,487 children. Obesity Facts 2017;10:559-68.

20 Hobbs MRet al. Understanding the relationship between deprivation, fastfood outlets, diet and body mass index: a structural equation modelling approach. J Epidemiology and Community Health 2019:73:861-6.

21 Statistics New Zealand. 2013 census QuickStats about a place. Auckland Region, 2013.

22 Auckland Council. Auckland profile: initial results from the 2013 census. Auckland: Auckland Council, 2014

23 Exeter DJ, Zhao J, Browne M, et al. Towards a new index of multiple Area-Level deprivation for Auckland, New Zealand. N Z Geog 2016;72:92-106.

24 Oliver M, McPhee J, Carroll P, et al. Neighbourhoods for active kids: study protocol for a cross-sectional examination of neighbourhood features and children's physical activity, active travel, independent mobility and body size. BMJ Open 2016;6: e013377.

25 Giles-Corti B, Timperio A, Cutt H, et al. Development of a reliable measure of walking within and outside the local neighborhood: reside's neighborhood physical activity questionnaire. Prev Med 2006;42:455-9.

26 Badland H, Donovan P, Mavoa S, et al. Assessing neighbourhood destination access for children: development of the NDAI-C audit tool. Environment and Planning B: Planning and Design 2015;42:1148-60.

27 Jones A. Child-Centred Methodology: A Means to Understanding Psychosocial Neglect and Harm in Cases of Migration: A Caribbean Context, in In: XVIIth ISPCAN International Congress on Child Abuse and Neglect. Hong Kong, China, 2008.
28 Oliver M, Parker K, Witten K, et al. Children's out-of-school independently mobile trips, active travel, and physical activity: a cross-sectional examination from the Kids in the City study. J Phys Act Health 2016;13:318-24.

29 Vallée J, Le Roux G, Chaix B, et al. The 'constant size neighbourhood trap' in accessibility and health studies. Urban Studies 2015;52:338-57.

30 Ni Mhurchu C, Vandevijvere S, Waterlander W, et al. Monitoring the availability of healthy and unhealthy foods and non-alcoholic beverages in community and consumer retail food environments globally. Obes Rev 2013;14 Suppl 1:108-19.

31 Mavoa S. Delineating Neighbourhood and Exposure in Built Environment and Physical Activity Research. Auckland, New Zealand: Massey University, 2015.

32 Witten $\mathrm{K}$, McCreanor T, Kearns R, et al. The impacts of a school closure on neighbourhood social cohesion: narratives from Invercargill, New Zealand. Health Place 2001;7:307-17.

33 Egli Vet al. Understanding children's neighbourhood destinations: presenting the KidsPoND framework 2019:1-15.

34 Vandevijvere S, Molloy J, Hassen de Medeiros N, et al. Unhealthy food marketing around New Zealand schools: a national study. Int J Public Health 2018;63:1099-107.

35 Vandevijvere S, Sushil Z, Exeter DJ, et al. Obesogenic retail food environments around New Zealand schools: a national study. Am J Prev Med 2016;51:e57-66.

36 Maddison R, Jiang Y, Vander Hoorn S, et al. Describing patterns of physical activity in adolescents using global positioning systems and accelerometry. Pediatr Exerc Sci 2010;22:392-407.

37 Atkinson J, Salmond C, Crampton P. NZDep2013 Index of Deprivation. Research Report. Wellington, New Zealand: Department of Public Health, University of Otago, 2014

38 Taylor RW, Williams SM, Grant AM, et al. Predictive ability of Waist-to-Height in relation to adiposity in children is not improved with age and sex-specific values. Obesity 2011;19:1062-8.

39 Ministry of education. school Deciles, 2016. Available: http://www.education.govt.nz/ school/running-a-school/resourcing/operational-funding/school-decile-ratings/ [Accessed 4 Jul 2016].

40 Ranganathan P, Pramesh CS, Buyse M. Common pitfalls in statistical analysis: clinical versus statistical significance. Perspect Clin Res 2015;6:169.

41 Wilkins E, Radley D, Morris M, et al. A systematic review employing the GeoFERN framework to examine methods, reporting quality and associations between the retai food environment and obesity. Health Place 2019;57:186-99.

42 Hobbs M, Griffiths C, Green MA, et al. Neighbourhood typologies and associations with body mass index and obesity: a cross-sectional study. Prev Med 2018;111:351-7.

43 Hobbs M, Griffiths C, Green MA, et al. Associations between the combined physical activity environment, socioeconomic status, and obesity: a cross-sectional study. Perspect Public Health 2018;138:169-72.

44 Burgoine T, Forouhi NG, Griffin SJ, et al. Does neighborhood fast-food outlet exposure amplify inequalities in diet and obesity? A cross-sectional study. Am J Clin Nutr 2016;103:1540-7.

45 Seliske L, Pickett W, Rosu A, et al. The number and type of food retailers surrounding schools and their association with lunchtime eating behaviours in students. Int J Behav Nutr Phys Act 2013;10:19.

46 Walton M, Pearce J, Day P. Examining the interaction between food outlets and outdoor food advertisements with primary school food environments. Health Place 2009;15:841-8.

47 Gram M. Buying food for the family: negotiations in parent/child supermarket Shopping: an observational study from Denmark and the United States. J Contemp Ethnogr 2015;44:169-95. 